\title{
The socio-economic background of immigrants affect the chances to get higher education in Sweden
}

\author{
Md. Ashrafuzzaman* \\ Department of Anthropology, University of Chittagong, Bangladesh \\ *E-mail address: frankashru@gamil.com, dvs13mas@student.lu.se
}

\begin{abstract}
The main reason behind gathering a great number of immigrants in Sweden is its neutral advocacy in world politics. Many of the immigrants have come to Sweden after completing their higher education in their own countries and want to work and live in Sweden. They prefer the socioeconomic condition of Sweden better than any other countries even from their own countries sometimes. My area of this research is "Socio-economic background and immigration". I reviewed books, articles, other secondary data and will try to show the position of immigrants through socioeconomic background as both are co-related. Immigration comes before socio-economic back ground or vice-versa. I will also try to focus on the position of education or what kind of educational facilities the immigrants are enjoying. 'Socio-economic background' and 'Effect of socio-economic background on higher education in Sweden' are the two points of my discussion. Here I will focus on the two points as well as 'Socio-economic background' \& Immigrant discussion make place this article respectively and the question is Does the socio-economic background of immigrants affect the chances to get higher education in Sweden? If so, then how it affects the chances? How does socio-economic and socio-cultural factors affect the educational attainment of higher education in second-generation immigrants in Sweden?
\end{abstract}

Keywords: Socio-economic background; immigrants; higher education; Sweden-Past-Present

\section{INTRODUCTION}

During 1851-1930 about 1.5 million Swedish left Sweden and reached the US in search of work though Sweden became favorable to the people of other countries since 1930.In the present day approximately $20 \%$ of all individuals living in Sweden have an immigrant background. During the 1950s, Sweden experienced a period of economic growth, which created a necessity for labour immigration. As a result, immigrants, especially from the Nordic countries and from the Southern part of Europe, started to become a bigger part of the Swedish society. However, in the 1970s, most of the immigrants came to Sweden for economical purpose as well as the number of immigrants population increased in the wake of political events in Chile in the 1970s - Poland, Iran and Iraq in the 1980s, and former Yugoslavia, Somalia and other parts of Africa in the 1990s . Naturally, the cultural and educational background of these more recent immigrants, who are mainly refugees, was also different from those of previous groups. In relation to the educational system, at present time over 15 per cent of children in Sweden have immigrant parents . This paper focuses upon how 
the category 'immigrant' is constituted and developed through education and adult newcomers. Immigration has become a part of human history in Sweden and it is already shown how it happened in near past. Roséna \& Bagga-Guptab (2013 ) wrote that Human beings' participation in institutional practices frames how they adjust to or challenge the label placed upon them in everyday practices. It is anazysed that during last 10 years, categorization in the immigration process was very important. And this categorization was done in the base of immigrants' education, skill, and originated country. The main reason behind gathering a great number of immigrants in Sweden is its neutral advocacy in world politics. Many of the immigrants have come to Sweden after completing their higher education in their own countries and want to work and live in Sweden. They prefer the socioeconomic condition of Sweden better than any other countries even from their own countries sometimes. During 1851-1930 about 1.5 million Swedish left Sweden and reached the US in search of work though Sweden became favorable to the people of other countries since 1930 ( Roséna and Sangeeta Bagga-Guptab,2013). Though, Sweden has created equal opportunity for all in the field of education through her education act. Since the early 1990s, Sweden has changed the education system dramatically among OECD countries. Immigrants students enjoy the facilities as native students enjoy. Education is compulsory in Sweden yet immigrant students are affected by different conditions and circumstances(Miho Taguma et al) Socio-economic background and migration are the two most important factors that are closely related why immigrant students are lagging behind from acquiring education in Sweden. In the early years of the 20th century, access to education for lower class children was a heavily debated topic in Sweden (Westling Allodi 2007). Since then universalism, equal rights to education and elimination of economic obstacles have been established as the leading principles of Swedish educational policy. Over the years great efforts have been made to ensure availability and accessibility and throughout the years the Swedish school system has put high value to create an equitable and fair school system independent of personal and family background (Westling Allodi 2007). However, with the emergence of neoliberal trends in the 1980s and the 1990s, a number of educational reforms have been developed and implemented into the Swedish school system (Berhanu 2010). As a consequence of this new wave of educational policies, statistics from the National Agency of Education have shown that pupils who are second-generation immigrants are overrepresented in special education programs in certain municipalities (Westling Allodi 2007). Furthermore, an increase in the marginalization and segregation of socially disadvantaged and ethnic minority groups is also shown by the statistics (Berhanu 2010).

\section{THEORETICAL FRAMEWORK \& METHODOLOGY}

The socio-economic background of immigrants affect the chances to get higher education in Sweden is the study object in this paper. Social capital theory will be applied in this study. Factors that are distinguished to be related to cultural and social capital will be given consideration when studying the perception of employers. Give a deeper understanding of in what way I will use cultural and social capital theory. I come from the assumption that people that have a higher social class background will also have higher capital both in the cultural and social aspects. Here I need to give reasons for the connection. I will also in more detail go into the specific factors that are considered with regards to respective capital. Campbell et.al. (1986), found that education attainments, family income and occupational prestige are positively related to personal social resources. Therefore, social capital could be 
considered as the intermediate variable linking socioeconomic status to educational expectations. In other words, second-generation immigrants with distinctive family socioeconomic status acquire different social capital, resulting in their educational expectations. Cultural Background, Guo \& Jamal $(2007,45)$ point out in their research that a more inclusive structure in regards to race and ethnicity, for individuals, within higher education can have structural changes at large. According to both Baum \& Flores (2011) and Tasiran \& Tezic $(2006,507)$ immigrants from Asian countries are more likely to become high educated students than immigrants from an example Africa. This study shows the process of selecting immigrants on the basis of upper education. Immigrants with higher education have more possibility to stay in Sweden. If their income is relatively high and age is below 40, they can stay here with social security. And immigrants with low education and poor income have poor possibility of staying here. On the other hand, Some of the articles are using statistical analyses while others focus more upon theoretical analytical methods. Those articles that are using statistics are diverse in how they analyse the statistical information. Either the research is based upon statistical mathematic measurements or a more comparative analytical methodology where they analyse the give statistics. Tasirin \& Tezic (2006) is an example of the first approach while Baum \& Flores (2011) is an example of the later. As stated above some authors focus less on statistic in their research instead they use a more theoretical approach in order to reach answers e.g. Guo \& Jamal (2007). Additionally, the purposes of selected methodology in the articles are diverse, even within the main methodological approaches. Some authors are using statistical analysis to test a given hypothesis in a Swedish context, e.g. Andersson et.al. $(2010,2676)$, while some authors try to evaluate difference over time within the Swedish higher educational system in regards to foreign students, e.g. DinguKyrklung $(2005,123)$. In general, they used the theoretical framework and the state of art both to define the variables they want to include in their analysis and to draw on possible explanations of the relations established between the variables in the quantitative analysis.

\section{SOCIOECONOMIC BACKGROUND OF THE IMMIGRANT'S OF SWEDEN, PAST \& PRESENT}

Sweden is populated with about nine million people. Immigrants to Sweden increased after the Second World War. Today, approximately $20 \%$ of all individuals living in Sweden have an immigrant background (Swedish Ministry for Foreign Affairs, 2001). But the number of immigrants population increased in the wake of political events in Chile in the 1970s Poland, Iran and Iraq in the 1980s, and former Yugoslavia, Somalia and other parts of Africa in the 1990s (Taguma et al.,2010.p.13;Opper 1983; Andersson et al.,2010.p.205).Political refugee and formation of mixed couple are important reasons of Sweden's increasing immigrants. To have a job in Sweden is easy for the European citizen but it is limited for the non-European citizens. Statistics show that more than 60 percent of the foreign-born academics are working in high positions(Dingu-Kyrklund,Elena.,2005.p.124-125). The number of immigrants increased dramatically till 1969 because of political turmoil all over the world. The flow of immigrants decreased considerably by 1970s. But by this time, half of the Swedish children were born of non-Swedish father or mother. By the year 1978, the proportion of non-Scandinavians was more than triple. In 1976, The Swedish National Bureau of Statistics found that if they would not let the immigrants enter into Sweden after 1944, their present population would be around 7.5 million less. But the immigrant population played an important role in the balance of birth/death ratio because the natives have a negative view 
regarding this (Opper, Susan.,1983.p.195-196).So, here we see that the social condition of the immigrant countries and Sweden increased the number of immigration in Sweden. It is already discussed that a great number of Swedish population are non-Swedish by born. At present, most of immigrants in Sweden are from ex-Yugoslavia, Bosnia-Herzegovina, Iraq, Iran, Poland and Turkey. The share of immigrants from less developed countries increased between 1980 and 2000 from about 13\% to about 36\% (Blume et al., 2005). In 2006, 15\% of the foreign born population were born in Finland, 7\% in Iraq, 6\% in Former Yugoslavia and about 5\% in Bosnia-Herzegovina and Iran respectively (OECD, 2008). The the Egalitarian Policies were friendly for both the immigrants and native, they experienced a bitter condition in the 1990s because of worldwide economic crisis. Even, the immigrants in Sweden were in much better condition than any other OECD countries.

At present more than $15 \%$ children are from immigrant parents. The number of immigrant pupils rose to 86,400 in 1979 while it was 30,000 only in 1975 (Opper, Susan.,1983.p.202).A great number of political refugees entered Sweden in the 1980s and 1990s. As a result of more and more immigrants, jobs became rare and immigrants started joining industrious labour (Andersson et al.,2010.p-206). About the immigrants, most of the achievements were positive and there were little gap regarding overall development. But this gap is being removed as the second generation Swedish immigrants are receiving inclusive school system. They are getting chance to uphold their own ability and knowledge( Hillmert, S.,2013.p.12-14).A projection from Statistics Sweden shows that by the year 2050 Sweden will reach a durable economic position and the immigrants will play important part. This fiscal impact is great in the labour market. It also shows that the immigrants will contribute by 1\% of its GDP (Ekberg, Jan.,2011.p.103).Like many other countries, increasing immigrants will increase the burden of public finance. But hopeful news is that most of the Swedish immigrants are young and engaged in different types of jobs. (Statistics Sweden 2004). From some study we find that employment situation was good up the 1970s. Recently a greater portion of immigrants are enjoying standard life while the other portion is suffering from different social problems including financial security (Ekberg, Jan.,2011.p.104). Immigrants' occupational position, occupational mobility, and incomes compared with those of nativeborn Swedes are the area of concerns. Some studies show that the intergenerational transfer of labour market position is much stronger among immigrants than among native Swedes (Rooth et al.,2006.p.57-58).

So, here we see that socio-economic background of the immigrants' country is causing them to be immigrants. Inhabitants of Iraq, Iran \& Chili are leaving their countries for turmoil political situation. History shows us that a great masses of political refugees took shelter in Sweden after the Second World War. Citizens of other European countries are also choosing Sweden because the working environment and scope of jobs are better than that of their own society. People from Asia and Africa prefer Sweden for the same reason. Bangladesh, India, Pakistan, Iraq, Iran, Bhutan, India, Afghanistan and many African citizens want to be shifted in Sweden because of their own socio-economic background. Theses developing countries cannot provide all the modern amenities even quality education to their citizens. Sometimes, deserving candidates having adequate knowledge, skill and experience cannot have desired higher education or jobs. These poor socio-economic conditions press them to be immigrants in any developed countries. For seeking immigration, people choose Sweden first. We have already described the friendly socio-economic condition of Sweden. Sweden always plays neutral role in world politics and they have a great sympathy for humanity. Sweden never considers immigrants a burden to them. Rather, they create policies to help the immigrants as well as to use them as resource. In Swedish society, there is not 
discrimination between a native Swedish and an immigrant. Both of them enjoy same kind of facilities. An immigrant child is never thought someone out of Swedish. Employment gratuity or education facilities in educational institution are equal for all. In some cases, immigrants cannot compete with the natives but Swedish socio-economic condition is not responsible for it. I have already shown that some immigrants are lagging behind for their knowledge and competence which they could not raise to standard level in their own country.

In short we may say that, the poor or defective socio-economic condition of immigrants made them to be immigrants. And at the same time, friendly socio-economic conditions and social security of Sweden attract them to be immigrants in Sweden.

\section{EFFECT OF SOCIO-ECONOMIC BACKGROUND ON HIGHER EDUCATION IN SWEDEN}

People face linguistic problem when they migrate from one geographical space to another. When human beings move across national borders they not only move between geographical spaces but they also become subjects within specific discourses that locate them within certain categories( Hillmert, S.,2013.p.8). It is already discussed that a great number of Swedish population are non-Swedish by born. In 1968 the Ministry of Eucation decided all immigrants should be given equal opportunities because immigrants can make Sweden more international even if they return to their original country. Decision was also taken that children would be allowed to learn mother tongue in parallel to learning Swedish because it would help them to understand subject matters easily. In 1974, the Minister of Education made new provision that every child of the age of six will receive pre-school education whether they are born in Sweden or not.(Opper, Susan.,1983.p.202-205)Therefore, by this discussion We can say that the Socio-economic background Sweden affects the immigrants students to get higher education in Sweden. Parental income was a very important issue on achieving higher education. Those whose parents earn comparatively high have more probability to study in high schools and university. Father's labour-income increased the probability of secondgeneration immigrants' education while mother's income affects education of the native children. Geographical origin is a big factor in achieving education of the immigrants. Study shows that immigrants of Asian origin possess much probability of achieving education. But the chances are lower for the African origins. The second generation immigrants with Swedish parent had more possibility of continuing upper-secondary education. Gender was also important in case of choosing type of education. Male were choosing technical education which helped them to get work easily and to earn much( Tasiran, Ali. et al.,2006.p.507).

So, we find that parental social, geographical and economical condition affect the second-generation immigrants' education much. If the parents have a strong income and work facility, children also have the higher probability of achieving higher education.

While analysing empirical evidences, Hillmert $(2013,7)$ points out in his research that migrants' students are often underprivileged regarding their educational situation in comparison to non-migrant students. In addition to this, it is also shown that the international variation between students in their relative situation is remarkably diverse. The situation for different immigrants coping with the Swedish educational system is diverse; immigrant youths from some countries finds the doors to educational system wide open whereas other groups often have a hard change for higher education. For instance, Tasiran \& Tezic (2006, $507)$ as well as Baum \& Flores $(2011,175)$ state that youths of Southeast Asian and European origin have a higher probability to enroll in university studies that youths from for an example 
Africa or Central America. In relation to this, Baum \& Flores $(2011,171)$ claims that this partly can be explained by characteristics of the different group of immigrants. Characteristics such as their country of origin, race, and parental socioeconomic status. Thus, to understand the situation for each immigrant it is important to bear in mind that each and every immigrant has brought along parts of their lives to their new country as well as that they have left other parts of their lives behind (Hammar 1980, 99). Higher educational attainment rates of immigrant students show that those whose parental socioeconomic background is not strong and whose parents have little education face significant barriers to enrolling and succeeding in postsecondary education (Baum \& Flores 2011, 171). As a result, the fact that students with immigrant background are facing increasing marginalisation and discrimination in the Swedish school systems, resulting in a growing difference in educational attainment, particularly university participation, compared to native born population and between different groups of immigrants (Teltemann 2010) leads us to the immigrants' educational attainment in relation to their background. It is important and interesting to evaluate the Swedish immigrants' educational attainment in relations to their background.

\section{INVESTIGATION}

Research has consistently found that socio-economic characteristics are key determinants in the educational expectations of immigrants' children. As the dominant paradigm in the study of educational attainment since the 1950s, status-attainment research has long established that family's socioeconomic status (SES) is strong and positively related to the academic success of certain second-generation immigrants, and their favourable attainment could predict eventual economic success (Haller \& Portes 1973). Factors that affect the increase or decrease for the situation of immigrant students are as follows:

Two levels of socioeconomic characteristics have been included in the previous research, based on the emergence of segmented assimilation theory which emphasizes the divergent paths of mobility for second-generation immigrants among different ethnic groups and argues it is important to look beyond the family background (Arzubiage et al., 2009), and its challenges to the traditional assimilation theory. Family-level Socioeconomic Characteristic: Hillmert $(2013,17)$ research has shown that parental education is a strong predictor of children's educational attainment and indicates the relevance of socio-economic background for educational performance in general. This argument by Hillmert is also supported by Baum \& Flores $(2011,174)$. They mention that, young people whose parents have no college involvement are much less likely than others to join and prosper in postsecondary education. Well-educated parents in Sweden tend to encourage their children to also become well educated (Johnson et al. 2011, 1271). Group-level Socioeconomic Characteristics: Based on segmented assimilation theory, along with immigrant selectivity, Feliciano (2006) incorporated two key group-level variables describing the pre- and postmigration SES of the first-generation immigrant groups in addition to the individual family level of parents' post-migration SES to examine their effect on educational expectations of immigrants' children. The results have shown that pre-migration educational status of immigrant group is significantly related to the expectation among second generation. Moreover, the effect of parents' post-migration SES on the expectation depends on the premigration group status. While educational expectations are constantly considered to be strongly related to educational attainment, it is reasonable to incorporate group-level socioeconomic variables into the research, however, this is absent in previous studies, 
therefore, it is of importance to include these variables and test their relationships with university participation in Sweden, which is one of the goals of our research (Feliciano 2006). Previous studies have identified two intermediate variables between socioeconomic background and educational attainment. Campbell et.al. (1986), found that education attainments, family income and occupational prestige are positively related to personal social resources. In other words, second-generation immigrants with distinctive family socioeconomic status acquire different social capital, resulting in their educational expectations.

In addition to educational aspiration, Picot \& Hou (2013) have identified secondary school performance as another intermediate variable between family background and educational attainment to explain the gap between students with and without immigrant backgrounds. They observed that Canadian-Swiss differences in immigrant educational outcomes implies that immigrant and educational policies are important to understand the attainment gap, and should also be incorporated into the question of social-economic background on immigrants' educational attainment. Moreover, the pattern connecting socioeconomic status with educational attainment also varies across different institutional environment, of which policy difference and school segregation are two aspects that have been identified. Picot and Hou (2013) have compared university participation in Switzerland and Canada and by using new longitudinal data, their observed Canadian-Swiss differences in immigrant educational outcomes implies that immigrant and educational policies are important to understand the attainment gap, and should also be incorporated into the question of social-economic background on immigrants' educational attainment. Predictor of children's educational attainment and indicates the relevance of socio-economic background for educational performance in general. This argument by Hillmert is also supported by Baum \& Flores $(2011,174)$. They mentioned that, young people whose parents have no college involvement are much less likely than others to join and prosper in postsecondary education. Well-educated parents in Sweden tend to encourage their children to also become well educated (Johnson et.al. 2010: 1272). Andersson et.al.(2010) have found that the rise in the minority population due to immigration has increased the level of school segregation and at the same time has brought variations in school performance across schools that affect student outcomes. School with a high population of minority students have low performance in comparison to those schools with a low presence of minority students.

\section{ARGUMENT}

The socio-economic perspective reaches the problem by emphasizing the difference in the socio-economic status of immigrant ethnic groups. However, based upon a number of studies that have shown the relatively small variance socioeconomic factors could explain academic performance. Ethnic background is one of the key factors that been argued to affect the overall pattern of educational attainment difference among groups. Guo \& Jamal (2007, 45) points out in their research that a more inclusive structure in regards to race and ethnicity, for individuals, within higher education can have structural changes at large. According to both Baum \& Flores (2011) and Tasiran \& Tezic $(2006,507)$ immigrants from Asian countries are more likely to become high educated students than immigrants from an example Africa or Central America. On the other hand, the socio-cultural perspective argues that the culture of ethnic groups and the context of the groups' reception in the receiving country also matter in explaining school achievement (Urban 2012). The conventional results of different articles 
came up with concerns of school segregation, parental education, social capital and ethnic background.

In contrast, some research has focused upon the institutional and organizational settings, the discourses and the policies of the Swedish educational system (Johansson et.al., 2007; Kamali, 2010; Bernahu, 2010). These research followed a critical analysis of the social structures and discourses that characterize Swedish society. For that reason, this research could be regarded as controversial, which questioned the idea of the variations and differences in performance and educational attainment. Hence, educational performance and attainment are explained by individual or group characteristics such as ethnic background or parental characteristics (parents' educational background-, income, socioeconomic status, support to their children education, or misunderstanding of the Swedish culture, as examples of this). On the contrary, some articles focus on the discourses and practices of the Swedish educational system as rather monoculture and ethnocentric, which can be regard as the reaffirmation and legitimization of inequality (Kamali, 2010). For instance, Bernahu (2010) argues that the difference in the school outcomes between immigrants and natives and the overrepresentation of immigrants in special education programs is multicasual and can be also seen as a problem of evaluation, diagnostic procedures and inappropriate interpretation of ethnic and cultural differences.

\section{CONCLUSION}

The research issues relating to the higher educational opportunities of immigrants in Sweden have change over time. For example, the changing pattern of immigrants, from native Swedes, either fellow Nordics or Europeans to refugees, has major impact on the integration pathways of immigrant students who came from out sides of Europe (Baum \& Flores 2011, 172). Inclusion of tuition fees also introduces a new chapter for the immigrant students, which needs to be analysed while doing research on the issues relating to the higher educational chances of immigrants in Sweden. The category "immigrant" is not a single category; rather it comprises different people with different ethnic and social background and countries of origin. Education attainment, school performance and educational choices are complex issues that suggest the existence of background factors (ethnic, social, economic, cultural) and the intergenerational influence of immigrants plays a very significant role in relation to their children's educational life. The Swedish social welfare state has been aiming at excluding the factor of parents' socioeconomic status for children's access to education, despite the active policies for educational equality, a number of studies have shown that compared to others with the same background, certain immigrant groups in Sweden tend to receive higher education, and there are larger differences between native and foreign-born students (Urban 2012).If we eye to history, we see that Sweden was always important in world politics, but not for its active participation in politics but for its humanitarian steps. It was always neutral in world politics and this is the reason why people chose Sweden as immigrant country. Sweden never disheartened anybody whether the person is a political refugee, student or job seekers. Sweden has a wide constitutional provision regarding education both for the native and the immigrants. It hardly shows any discrimination on imparting education. People of different geographical position left their own country because of their poor socio-economic condition. At the same time they choose Sweden because of its favourable socio-economic condition. At the same time Sweden imparts education to all regardless of native or immigrants. In the society of Sweden and in the provisions of constitution, the native and immigrants enjoy same 
facilities in educational institutions. Even, Sweden makes it easy for the immigrants students to study here. They can choose subjects and can study international language like English. Expense is also favourable for them. The Swedish government provides a wide range of scholarship for the immigrants and it is very helpful for them in the way of achieving higher education. Though the immigrants sometimes lag behind from the native and European immigrants, the socio-economic condition of Sweden is not responsible for this. Their own socio-economic condition is primarily responsible. So, at the end of this analysis, we can say that immigrants leave their own country because of their own poor socio-economic back ground. And they choose Sweden because its favourable socio-economic background which I have already discussed. Therefore we can conclude: both the socio-economic background of immigrants and Sweden affect the chances to get higher education in Sweden.

\section{References}

[1] Andersson, Eva; Östh, John \& Malmberg, Bo (2010): Ethnic segregation and performance inequality in the Swedish school system: A regional perspective: Environment and Planning, 42(11), 2674-2686.

[2] Andersson,Per. \& Fejes, Andreas.,2010."Mobility of knowledge as a recognition challenge: experiences from Sweden", Routledge, Int. J. Of Lifelong Education, VOL. 29, NO. 2 ,p.201-218, Online available at: [Lund University Libraries] On: November7, 2013.

[3] Baum, Sandy \& Flores, Stella M (2011): Higher Education and Children in Immigrant Families: The future of Children, 21(1), 171-193

[4] Berhanu, Girma 2010: Even in Sweden? Excluding the Included: Some Reflections on the Consequences of New Policies on Educational Processes and Outcomes, and Equity in Education: International Journal Of Special Education, 25 (3), 148-159.

[5] Best, J., 2001. Damned Lies and Statistics. Untangling Numbers From the Media, Politicians, and Activists. Los Angeles: University of California Press.

[6] Dingu-Kyrklung, Elena (2005): Migration and Recognition of Diplomas in Sweden: European Journal of Education. 40(2), 123-141.

[7] Bryman, A., 1988. Quantitaty and Quality in Social Research. London/New York: Routledge.

Dingu-Kyrklund, Elena.,2005." Migration and Recognition of Diplomas in Sweden", Blackwell Ltd., UK, USA, European Journal of Education, Vol. 40, No. 2, p.123-138

[8] Ekberg, Jan.,2011." Will Future Immigration to Sweden Make it Easier to Finance the Welfare System?" ,Springer Science+Business Media B.V.,Vol. 27,p.103-124, Online available at: [Lund University Libraries] On: November7, 2013.

[9] Frippiat \& Marquis.,2010. Web Surveys in the Social Sciences: An Overview

[10] Guo, Shibao \& Jamal, Zenobia (2007): Nurturing Cultural Diversity in Higher Education: A Critical Review of Selected Models: Canadian Journal of Higher Education, 37(3), 27-49.

[11] Hammar, Tomas (1980): Immigration Research in Sweden. International Migration Review .14(1). 93-115 
[12]Hillmert, Steffen.,2013. "Links between immigration and social inequality in education: A comparison among five European countries", Elsevier, Research in Social Stratification and Mobility 32, p. 7-23.Online available at :www.sciencedirect.com, ,(Accessed on November 07,2013).

[13]Haller, Archibald O \& Portes, Alejandro.,1973. Status attainment processes: Sociology of education, 46(1), 51-91.

[14] Johansson, Olof; Davis, Anna Kay \& Geijer, Luule., 2007. A perspective on diversity, equality and equity in Swedish schools: School Leadership And Management, 27, 1() 2133.

[15]Johnson, Wendy Brad; Deary, Ian John; Silventoinen, Karri; Tynelius, Per \& Rasmussen, Finn Vejlø.,2010. Family Background Buys an Education in Minnesota but Not in Sweden: Psychological science, 21(9) 1266-1273.

[16] Jonsson, Jan O. \& Rudolphi, Frida .,2011. Weak performance-strong determination: School achievement and educational choice among children of immigrants in Sweden: European Sociological Review, 27(4), 487-508.

[17] Järvinen, M., 2007. Pierre Bourdieu. In: Andersen, H. \& Kaspersen, B. L. (eds.): Klassisk og moderne samfundsteori. 4. edition. Copenhagen, Hans Reitzels Forlag.

[18] Kamali, Mascoud., 2000. The role of educational institutions in the clientization of immigrants: the Swedish case: Intercultural Education, 11 (2), 179-193.

[19] Opper, Susan.,1983. Multiculturalism in Sweden: A Case of Assimilation and Integration: Taylor \& Francis, Ltd, Comparative Education, 19(2) 193-212

[20]Nekby, Lena.,2006. "The emigration of immigrants, return vs onward migration: evidence from Sweden", Springer-Verlag, P.197-226, Online available at: [Lund University Libraries] On: November 7, 2013.

[21] Opper, Susan.,1983. "Multiculturalism in Sweden: A Case of Assimilation and Integration", Taylor \& Francis, Ltd, Comparative Education, Vol. 19, No. 2, Special Number (7): Education and the Diversity of Cultures pp. 193-212,Online available at: http://www.jstor.org/stable/3098832, (Accessed on November 07,2013).

[22]Rooth, Dan-Olof. and Ekberg,Jan., 2006 "Occupational Mobility for Immigrants in Sweden" ,Blackwell Ltd.,UK,USA, International Migration Vol. 44 (2) ,P.57-77, Online available at: [Lund University Libraries] On: November7, 2013.

[23]Rosén, K. Jenny., a \& Gupta, B. Sangeeta.,2013." Shifting identity positions in the development of language education for immigrants: an analysis of discourses associated with 'Swedish for immigrants", Routledge, Language, Culture and Curriculum, 2013 Vol. 26, No. 1, 68-88, Online available at: [Lund University Libraries] On: November7, 2013.

[24] Silfver, A-L., (2010): Emancipation or neo-colonisation? Global gender mainstreaming policies, Swedish gender equality politics and local negotiations about putting gender into education reforms in the Lao people's Democratic Republic. In: Compare: A journal of Comparative and International Education 40 (4), pp: 479-495.

[25] Swedish Ministry of Education and Research (2009), "OECD Review of Migrant Education - Country Background Report for Sweden", Online available at:www.oecd.org/dataoecd/8/42/42485410.pdf. (Accessed on November 10.2013) 
[26] Swedish Ministry of Foreign Affairs, Department for Migration and Asylum Policy (2001), Sweden in 2000 - A Country of Migration. Past, Present, Future, Stockholm.

[27] Taguma, Miho., Kim, Moonhee., Brink, Satya. and Teltemann, Janna.,2010. OECD (ORGANISATION FOR ECONOMIC CO-OPERATION AND DEVELOPMENT) Reviews of Migrant Education, Sweden.

[28] Tasiran, Ali. \& Teic,Kerem.,2006 ." Parental Income and Continuing Education of Second Generation Immigrants in Sweden",Routledge, International Review of Applied Economics, Vol. 20, No. 4, 491-514, Online available at: [Lund University Libraries] On: November7, 2013. 